\title{
The Dueling Influences on Stigma toward Mental Illness: Effects of Interpersonal Familiarity and Stigmatizing Mediated Portrayals of Mental Illness on Attitudes
}

\author{
Bridget Rubenking ${ }^{1}$, Cheryl Campanella Bracken ${ }^{2}$ \\ ${ }^{1}$ University of Central Florida, USA \\ ${ }^{2}$ Cleveland State University, USA \\ Correspondence: Bridget Rubenking, University of Central Florida, USA
}

Received: October 8, 2015 Accepted: October 14, 2015 Online Published: October 21, 2015

doi:10.11114/smc.v3i2.1130

URL: http://dx.doi.org/10.11114/smc.v3i2.1130

\begin{abstract}
Popular media is both a common source for information about mental illness and notorious for its disproportionately negative and violent portrayals of those with mental illness. This research undertook an experiment $(N=92)$ to explore the competing influences of mass communication messages and interpersonal familiarity/ experience with people with mental illness on stigmatizing attitudes toward the mentally ill. Results demonstrate that exposure to negative, violent mediated portrayals of the mentally ill increase stigmatizing attitudes toward the mentally ill, while exposure to positive, sympathetic portrayals of the mentally ill relates to less stigmatizing attitudes toward the mentally ill. Greater interpersonal familiarity with those with mental illness was related to less stigmatizing attitudes toward the mentally ill regardless of viewing condition. Transportation and presence experienced while viewing the narratives with mental illness portrayals was proposed as a contributing mechanism behind adopting story consistent beliefs, but it was not related to adopting narrative consistent attitudes.
\end{abstract}

Keywords: mental illness, stigma, transportation, presence, attitude change

\section{Introduction}

The media is an important source for news and information about mental illness among Americans (Robert Wood Johnson Foundation, 1992; Wahl, 1995). However, a large literature demonstrates that media portrayals of mental illness are disproportionately negative and stigmatizing (Angelini, Nadorff, Shin, Gantz, \& Lang, 2006; Coverdale, Nairn, \& Classen, 2002; Pirkis, Blood, Francis, \& McCaullem, 2005; Sieff, 2003). Characters with mental illness in TV content are both one of the most violent and the most victimized groups on television (Gerbner, 1998; Klin \& Lemish, 2008; Philo, 1996; Rose, 1998). The mentally ill are typically shown with no other social identity cues and are even filmed in a distinct way - alone and close-up - as compared to their non-mentally ill counterparts (Wahl \& Roth, 1982).

Survey and experimental data in recent decades demonstrate that these portrayals perpetuate stigma toward persons with mental illness (see review, Pirkis, Blood, Francis, \& McCallum, 2014) and may further contribute to the low percentage of people suffering from mental illness who seek treatment (Crisp, Gelder, Rix, Meltzer \& Rowlands, 2000; Link, Phelan, \& Bresnahan, 1999). This study explores two possible sources of influence on stigma toward the mentally ill and one proposed mechanism for attitude change. Specifically, it explores how transportation and telepresence experienced while viewing entertainment TV narratives may function as an underlying mechanism for adopting story consistent attitudes toward people with mental illness. It additionally explores how interpersonal familiarity or experience with people with mental illness may contribute to more or less stigmatizing attitudes toward the mentally ill.

\section{Background}

\subsection{Attitude Change and Entertainment Media}

Previous research from a number of perspectives demonstrates that individuals' real world attitudes and beliefs are influenced by narratives presented in entertainment media, and specifically in television messages. These include traditions such as transportation and narrative persuasion (Green \& Brock, 2000; 2002), entertainment-education, E-E, and the extended elaboration likelihood model (Slater, 2002; Slater \& Rouner, 2002), as well as cultivation theory (Gerbner, Gross, Morgan \& Signorelli, 1980). The ability of popular entertainment to change attitudes in pro-social 
ways (Moyer-Guse \& Nabi, 2010; Murphy, Frank, Moran, \& Patnoe-Woodley, 2011) has been studied somewhat extensively under E-E frameworks. Research on fictional narratives' influence on attitudes on controversial issues (Igartua \& Barrios, 2012; Slater, Rouner, \& Long, 2006) is not quite as extensive, though the theoretical frameworks employed by both overlap.

For instance, Slater et al. (2006) explores attitude change based on exposure to controversial political and policy positions presented in hour-long TV dramas. They report mixed results: Story consistent attitude change occurred post-exposure to a pro-death penalty narrative, but not in response to a pro-gay marriage narrative. The authors suggest three possible mechanisms underlying narrative persuasion: Immersion, cognitive elaboration, and priming of relevant underlying values. A different study explores attitudes toward social welfare support systems based on exposure to video narratives on welfare systems that were presented as either fiction or non-fiction. They found no main effect for the labeling of the video narratives as fiction or non-fiction, though did report interaction effects with participants' need for cognition.

A study contrasting the influence of narrative and non-narrative video exposure finds that a pro safe sex TV drama increased safe sex intentions among females, but not among males, whereas exposure to a non-narrative pro-sex stimulus did not increase safe sex intentions among either gender (Moyer-Guse \& Nabi, 2010). Interestingly, the same research found that transportation experienced while viewing the narrative stimuli led to increased counter-arguing, although increased counter-arguing was not linked to safe sex behavioral intentions. The related concept of identification with a main character has been studied as a mechanism in attitude change as well. An experiment examining the influence of a film presenting a controversial or negative view of religion on attitudes toward religion was conducted (Igartua \& Barrios, 2012). They report main effects for exposure to the film, Camino, such that those exposed to the film report more negative attitudes toward religion, and those who report greater identification with the main character report story-consistent attitudes to an even greater degree. Unintended or undesirable attitude change based on exposure to narratives has also been studied. Lee and Leets (2002) find that messages greater in narrative story-telling as compared to more factual presentations which included implicit racist sentiments (as compared to explicit) are more persuasive than all other combinations of narrative structure and implicit/explicit racist sentiments. Studies examining attitude change based on exposure to video narratives typically find some effects for some groups of participants, however, clear cut main effects on attitude adoption based on single exposures remains a somewhat elusive result.

More specific to the current study, learning from entertainment narrative portrayals of depictions of mental illness and adopting attitudes based on them has been studied previously. A study that exposed participants to a feature-length film about a woman's struggle with schizophrenia reports less stigmatization and significant knowledge gain only when participants watched the film followed by an educational trailer. Exposure to the film alone led to an increase in negative attitudes toward people with mental illness (Ritterfield \& Jin, 2006). Thornton and Wahl (1996) also report more tolerant views of persons with mental illness after exposure to prophylactic stimuli in their study of news stories presenting a violent murderer as a person with mental illness. However, without the corrective additional stimuli, more negative attitudes emerge post exposure to the news stories. Other experimental research generally supports that exposure to stigmatizing portrayals of mental illness results in more stigmatized attitudes or judgments about those with mental illness (Wahl \& Lefkowitz, 1989; Taylor \& Dear, 1981). Interestingly, a survey study taking a cultivation approach found no effects of overall amount of TV viewing on attitudes toward the mentally ill, though greater TV viewing was predictive of some, but not all, measures of self-reported greater social distancing from people with mental illness (Diefenbach \& West, 2007).

\subsection{Interpersonal Familiarity with Mental Illness and Attitudes}

Data demonstrates that a large majority of individuals are exposed to mental illness via mediated portrayals. Corrigan et al., (2001) find that $90 \%$ of a college undergraduate student sample report greater exposure to someone with mental illness via media depictions than interpersonally. Generally, smaller percentages of various populations report interpersonal contact, or familiarity with someone who suffers from a mental illness. The pattern of data on the influence of interpersonal familiarity with mental illness is somewhat clearer than the data on the influence of stigmatizing mass media depictions of mental illness on attitudes and stigma expressed toward the mentally ill. Increased interpersonal familiarity with persons with mental illness is associated with less stigmatizing views toward the mentally ill (Couture \& Penn, 2003). A review of research on interpersonal contact and stigma toward the mentally ill report that those with increased familiarity with people with mental are: Less likely to endorse negative attitudes toward the mentally ill (Read \& Harre, 2001); less likely to support restrictive limitations on the mentally ill (Ingamells et al. 1996); less likely to require greater social distance from the mentally ill (Chung et al., 2001; Corrigan et al., 2001); and less likely to perceive the mentally ill as dangerous (Penn, Kommana, Mansfield, \& Link, 1999). 
In a key study exploring interpersonal familiarity with mental illness and exposure to video entertainment narratives featuring mental illness, Caputo and Rouner (2011) report no direct effect of interpersonal familiarity/ experience with mental illness on self-reported social distancing behavior, such that participants did not differ in how willing they were to interact with a person with mental illness based on how much interpersonal exposure to mental illness they reported having. Increased familiarity with mental illness did, however, serve to increase both involvement in, and the relevance of, a film portraying a character struggling with mental illness (Caputo \& Rouner, 2011). It is likely that the general valence or affect associated with one's interpersonal and mediated experiences with mental illness play a role in attitudes toward the mentally ill and social distancing. Quite simply, it is logical to ask if someone's interpersonal experiences with others suffering mental illness left them hopeful, encouraged, fearful, or disappointed. Likewise, it should matter if a mediated portrayal of mental illness is about overcoming difficulties, or about a schizophrenic on a murderous rampage. Indeed, others have pointed to the need for more clarification on the nature of interpersonal interactions with those with mental illness and the various ways in which attitudes and social distance measures are utilized (Couture \& Penn, 2003). More recent research summarizing the state of mental illness stigma in various populations offers positive and negative news. There has been an increase in acceptance of mental illness diagnoses, need for treatment, and an understanding of the underlying biological correlates of mental illness over recent decades. However, stigmatizing responses, beliefs about the dangerousness of the mentally ill, and want for greater social distance from the mentally ill have remained consistent (Pescolido, 2013; Schomerus, 2012). Based on the previous literature, hypotheses 1 and 2 are posed:

H1: Exposure to a stigmatizing portrayal of characters with mental illness will result in more negative, stigmatized attitudes toward the mentally ill, and exposure to a sympathetic portrayal of characters with mental illness will result in more positive, less stigmatizing attitudes.

H2: Increased interpersonal familiarity with mental illness will lead to less stigmatized attitudes toward the mentally ill, regardless of experimental exposure condition.

\subsection{Transportation and Telepresence}

Previous research provides support that exposure to negative, stigmatizing portrayals of mental illness and exposure to positive, corrective portrayals of mental illness shape attitudes toward the mentally ill, but the mechanisms by which this occurs remain less clear. Determining these mechanisms has been a recent focus of research. Studies have explored various functional explanations for attitude change based on exposure to entertainment narratives, including involvement with specific characters (Iguartua \& Barrios, 20121 Murphy et al., 2011), emotional reactions (Murphy et al., 2011), and transportation into the narrative (Green \& Brock, 2000; Moyer-Guse \& Nabi, 2010; Murphy et al., 2011; Slater et al., 2006).

Transportation refers to how absorbed or transported into a story a person may become, and the extent to which their real world beliefs change as a result of the story (Green \& Brock, 2000; 2002). Being transported into a narrative is an integrative "melding of attention, imagery, and feelings" (p. 701, Green \& Brock, 2000). Transportation has been explored previously as a persuasive mechanism in the context of narratives about mental illness (Green \& Brock, 2000; Caputo \& Rouner, 2011). Individuals may lose access to some real-world facts while experiencing the narrative and adopt beliefs that the narrative encourages instead (Green \& Brock, 2000). While the amount of attention and critical thinking about the message is a key factor in determining how individuals process content in dual-process models of persuasion, Green and Brock (2000) posit that the immersion of individuals into narratives produces a distinct mechanism.

Research on transportation, narrative and attitude change occurs with narratives across mediums, including text (Gerrig, 1993; Green \& Brock, 2000) film (Busselle \& Bilandzic, 2009; Dal Cin et al., 2004), television dramas (Slater et al., 2006), and public service announcements (Tal-Or, Boninger, Poran, \& Gleicher, 2004; Stitt \& Nabi, 2005). The original study that accompanied Green and Brock's (2000) seminal transportation-imagery model piece measures transportation into a gruesome text narrative about a psychiatric patient murdering a young girl at a shopping mall. Participants who report greater transportation also report that violence is more likely to occur in real life and that psychiatric patients' freedoms should be restricted. The other three studies presented in Green and Brock (2000) found similar results: Greater levels of transportation are related to increased agreement with story-consistent beliefs.

The importance of immersion is notable in both transportation and telepresence. Telepresence is often defined as a sense of "being there." From Bracken, Petty, Guha, \& Rubenking (2010), telepresence is conceptualized as "Requiring the use of technology and resulting in a psychological state in which media users voluntarily suspend the experience of mediation in order to feel a sense of connection with the mediated content they are using (i.e. connection to characters, involvement in the story line)," (p. 126). While transportation is viewed as dependent upon characteristics of both the user and the narrative, telepresence is viewed as dependent upon both characteristics of the user and the media content 
and technology. Despite the prominent study of telepresence in virtual reality environments, telepresence can be experienced in any medium, from virtual reality to books (IJsselsteijn, 2003). User enjoyment or interest in the content at hand may also influence telepresence, as it does transportation.

The similarities between transportation and telepresence can be exemplified through the similar variables that are used to produce increased feelings of both constructs. Transportation is one dimension of Lombard and Ditton's (1997) six dimensions of telepresence. Bracken (2005) states that both telepresence and transportation focus on "the perceptual process by which media users are willing to ignore and transcend the technology they are using to access the content," (p.127). Narrative may influence telepresence: Individuals playing video games with a narrative present, as well as those who were exposed to a narrative about a video game before playing, both report greater telepresence experienced while playing (Schneider, 2004)

In one of the few discussions on the similarities and differences between transportation and telepresence, Busselle and Bilandzic (2006) point to identification as a state or ability that differentiates transportation from concepts such as flow and telepresence. They posit that adopting the point of view offered by a story is distinctive of processing of narratives. Despite the conceptual overlaps, and the finding that the presence of a narrative serves to increase telepresence, measuring both concepts in response to the same stimuli has been largely overlooked.

Previous work has examined telepresence and persuasion. In general, greater feelings of telepresence relate to greater attitude confidence and purchasing intention (Kim and Biocca, 1997), greater product knowledge and more positive brand attitudes (Li, Daughtery, \& Biocca, 2001), and greater motivation to process message content (Skalski \& Tamborini, 2007). So,

$\mathrm{H} 3$ : Greater transportation $(\mathrm{H} 3 \mathrm{a})$ and greater telepresence $(\mathrm{H} 3 \mathrm{~b})$ will be positively related to increased endorsements of story consistent beliefs in both the stigmatizing and sympathetic portrayal experimental exposure conditions.

H4: Transportation and telepresence will be positively related.

\section{Methods}

In order to examine attitudes toward the mentally ill as determined by exposure to differing mediated portrayals of the mentally ill and interpersonal experience with the mentally ill, an experimental study was conducted. The study followed a between-subjects, three-condition design, in which participants $(N=92)$ were assigned to one of three TV exposure conditions: Stigmatizing portrayal of mental illness $(N=35)$, sympathetic portrayal of mental illness $(N=23)$, or no portrayal of mental illness (control, $N=34$ ).

Participants were greeted and gave informed consent prior to being seated in experimental rooms equipped with comfortable chairs and large screen televisions. After individually viewing one of the three episodes of Law \& Order: $S V U$, participants completed questionnaires which included measures of transportation and telepresence experienced during viewing, as well as cued recall memory for content in the messages, personal experience with those with mental illness, and attitudes toward those with mental illness. Participants were all undergraduate students at a Midwestern University in the United States who received course or extra credit for their participation. The sample was $57.3 \%$ female and ranged in age from 18 to $47(M=23.0, S D=5.10)$. All procedures were conducted in compliance with approved protocols from the university's Institutional Review Board.

\subsection{Stimuli}

The stimuli used were three different episodes of Law\& Order: SVU, a popular crime drama and one of the more successful of the long-running Law \& Order franchise. Each episode begins with the discovery or search for a young female victim and continues with the same primary detectives interviewing multiple suspects before finding the guilty party. The control condition was chosen because there was no mention of mental illness, nor characterization of someone with mental illness. The stigmatizing condition stimulus was chosen because the episode centered on the main suspect, whose schizophrenia was repeatedly discussed as the main motivation behind his crimes. The sympathetic condition portrayal found the detectives aggressively and wrongfully pursuing multiple suspects who suffered from schizophrenia only to find the actual murderer was an ex-convict motivated by greed - not mental illness - to commit murder. Manipulation checks were completed in order to establish agreement among participants about the characterization of mental illness. Participants in each condition were asked about the presence of mental illness. Those in both the stigmatizing portrayal condition $(M=6.23, S D=1.24)$ and sympathetic portrayal condition $(M=5.91, S D=$ $1.79)$ significantly agree on the presence of mental illness on a 7-point scale more so than those in the control condition $(M=2.32, S D=1.79, F(2,89)=64.746, p<.001)$. Tukey post hoc tests indicated no difference in perceived presence of mental illness across the two experimental conditions $(p=.727)$. Participants also responded to 10 True/False items about the content they viewed. One participant's data was discarded for failing to correctly answer items. 


\subsection{Measures}

\subsubsection{Transportation}

Transportation was measured with Green and Brock's (2000) transportation-imagery model Scale, with slight modifications in wording to adjust for TV content. The 12-item scale includes items intended to capture imagery, affect, and attentional focus. The scale reached a Cronbach's $\alpha=.819$.

\subsubsection{Telepresence}

Three sub-dimensions of telepresence from Lombard, Weinstein, and Ditton's seven-dimension (2011) Temple Presence Inventory were measured: Spatial presence, immersion, and social realism. Per the scale authors, these items can be used together or separately. The combined presence measure as well as the sub-dimensions of presence scales met acceptable reliability coefficients, including spatial presence $(\alpha=.855)$, immersion (mental engagement) $(\alpha=.854)$, social realism $(\alpha=.799)$ and all presence items combined $(\alpha=.881)$.

\subsubsection{Familiarity with Mental Illness}

Participants responded to a single item measuring their agreement with the statement, "I am in regular contact with someone who suffers from either a minor or severe mental illness," on a 7 point scale.

\subsubsection{Attitudes toward Those with Mental Illness}

Attitudes toward those with mental illness were measured with an 8-item scale developed to indicate social desirability and violence perceptions about the mentally ill. These items were mixed with other items gauging attitudes about violent crime and other social issues, totaling 30 in all. Some items were modified from the Community Attitudes Toward the Mentally Ill scale (CAMI) developed by Taylor and Dear (1981), while others were newly developed. Higher numbers on this scale represent more negative or stigmatized attitudes toward the mentally ill. This 8 -item measure achieved a Cronbach's Alpha of .746.

\section{Results}

Hypothesis 1 predicts that exposure to the stigmatizing portrayal of characters with mental illness results in more negative, stigmatized attitudes toward the mentally ill, and that exposure to the sympathetic portrayal stimuli results in less negative, stigmatizing attitudes. A univariate analysis of variance tests how condition influenced attitudes toward the mentally ill. Those in the stigmatizing portrayal condition report the most negative, stigmatizing attitudes toward the mentally ill, $(M=3.76, S D=1.07)$, followed by those in the control condition $(M=3.49, S D=.95)$, and then by those in the sympathetic portrayal condition $(M=3.07, S D=.97, F(2,91)=3.315, p<.05, \mu=.069$. Tukey post hoc tests demonstrate that the difference between attitudes of those in the stigmatizing and sympathetic portrayal conditions significantly differ $(p<.05)$. Hypothesis 1 is supported.

Hypothesis 2 predicts that those with greater interpersonal familiarity/ experience with mental illness report more positive, less stigmatizing attitudes toward the mentally ill as compared to those with less familiarity, regardless of exposure condition. A regression analysis was used to determine the direction and strength of effect that personal familiarity with those with mental illness has on stigmatizing attitudes. After controlling for age and gender in the first block, the regression revealed familiarity had the predicted effect on attitudes: $F(3,90)=4.274, p<.001 ; \beta=-.354, p$ $<.05$, Adjusted $\Delta R^{2}=.098$ ). Familiarity with persons with mental illness accounted for $9.8 \%$ of variance in stigmatizing attitudes toward the mentally ill, such that those with more familiarity showed less stigmatizing attitudes. Hypothesis 2 is supported. An ANOVA testing the interaction effects of condition and those high and low in familiarity with persons with mental illness revealed no significant interaction.

Hypotheses $3 \mathrm{a}$ and $3 \mathrm{~b}$ predicts that greater transportation and telepresence leads to increased story consistent beliefs, such that when a person feels a greater sense of telepresence or transportation, they are more likely to express story-consistent beliefs about persons with mental illness. First, a univariate analysis of variance is conducted to test whether transportation and telepresence were similar across conditions. Self-reported transportation across conditions does not significantly differ, with an overall $M=4.31, S D=.91$, nor does the combined telepresence measure, $M=3.77$, $S D=.95$. For both experimental conditions, regressions including age and gender controlled for in the first block that regressed transportation and presence on stigmatizing attitudes toward the mentally ill are conducted. Both the regression in the stigmatizing portrayal condition $(p=.810)$ and the positive, sympathetic portrayal condition $(p=.125)$ revealed no significant effects for transportation and presence on adopting story-consistent attitudes toward the mentally ill. Hypothesis 3 is not supported.

The fourth and final hypothesis predicts a positive relationship between transportation and telepresence. The combined telepresence measure and transportation share a moderate to high correlation, $r^{2}=.681, p<.001$. The sub dimensions also all shared significant correlations with transportation: with immersion sharing an $r^{2}=.678, p<.001$, followed by 
social realism, $r^{2}=.464, p<.001$, and spatial presence $r^{2}=.451, p<.001$. Hypothesis 4 is supported.

\section{Discussion}

The results of this study support the influence of both mediated representations of characters with mental illness on attitudes toward people with mental illness, as well as the influence of interpersonal familiarity with mental illness. Individuals with greater interpersonal familiarity with mental illness report less stigmatized attitudes toward those with mental illness, as do those who viewed a TV narrative with a positive, sympathetic portrayal of a character with mental illness. This is somewhat mixed news for those concerned with combating stigma toward those with mental illness. Content analyses through the years demonstrate that the mentally ill are portrayed in a stigmatizing, violent context in the mass media (Coverdale et al., 2002; Philo, 1996; Pirkis, et al, 2006; Rose, 1998), and this study lends support to previous empirical evidence that exposure to these messages results in adapting story consistent beliefs to some degree. The bright side is that those who view positive, sympathetic portrayals of characters with mental illness report more favorable and positive attitudes toward those with mental illness (though these attitudes were not significantly different from those in a control condition).

This study suggests that the role of interpersonal familiarity with mental illness should not be ignored as a contributing influence to attitudes toward those with mental illness, despite the overwhelming exposure to mental illness in mass media messages. Communication research has a long tradition of studying the relative weights of interpersonal and mass communication messages on attitude and behavior change. One of our early seminal theories applied widely, Diffusion of Innovations, notes that targeted interpersonal influence is more effective at changing attitudes, while mass mediated messages are more valuable at spreading information (Rogers, 2003). In today's converging media landscape, the nature of both the interpersonal and mass mediated messages individuals encounter demand further attention. Research that directly compares the weights or relative influence of mass and interpersonal communication messages on attitudes toward the mentally ill would be a fruitful area for future research.

Lastly, while hypothesis 4 is supported: transportation and telepresence were related, neither of these concepts was found to be related to story-consistent attitude adoption across conditions (H3). Transportation and telepresence were also found to not significantly differ across experimental conditions. Transportation is defined as both the process of feeling transported to the story world and the resulting attitude change (Green \& Brock, 2000). This study's findings are then inconsistent with Green \& Brock's conceptualization of transportation both as the feeling of being transported and resulting attitude change. This study's mean transportation scale was similar to that found in Green \& Brock's (2000) study, though increased feelings of transportation did not yield an increase in adapting story-consistent beliefs.

More research and clarification of the relationship between the experience of feeling transported and attitude change should be investigated. Previous research examining telepresence as a mediator of persuasion did utilize persuasive content, such as commercials or PSAs. In addition, a number of them examined social telepresence (e.g. Skalski \& Tamborini, 2007) as opposed to spatial or physical telepresence, as this study did. On the transportation front, a meta-analysis that explored studies that experimentally manipulate various involvement measures with media reveals when experimental manipulations of transportation had a greater effect in persuasive messages as compared to entertainment messages (Tukachinsky, 2015). These content differences may account for the lack of a significant relationship in the present study. While increased telepresence and transportation may enhance positive evaluations in purposefully persuasive content, perhaps the effect of increased presence and transportation in narrative content is too subtle to influence social beliefs presented in the narrative.

A further limitation of the study was the relatively small sample size. Telepresence research rarely uses group administration of stimuli, since the feeling of "being there," is contingent on both the mediated world being enticing and absorbing, and the "real world," being hospitable to departing into the mediated world. Future research should continue to explore the conditions in which experiences of telepresence and transportation encourage attitude change (Bracken, 2005). Despite differences in the prominence given to certain variables or constructs within the transportation and telepresence fields of research, the overlap between constructs seems increasingly apparent as research in the transportation field continues to utilize newer media, while at the same time in the telepresence literature, there appears to be a shift in ideology away from the ultimate importance of modality vividness in favor of a mental models approach (Wirth et al., 2007), wherein presence is viewed as a phenomenon that occurs within individuals' brains. The two areas seem to be progressing toward one another and the relationship should be further explored.

Future research could additionally benefit from a closer examination of the general affect or valence and arousal and resulting emotions experienced as an effect of various interpersonal and mass mediated messages about mental illness. Additional cognitive variables could be explored, as should enjoyment. This study provides a useful addition to the literature on the ability of both interpersonal familiarity with mental illness and exposure to stigmatizing and non-stigmatizing portrayals of mental illness in entertainment narratives, while also providing an interesting lack of 
support for transportation and telepresence experienced as a mechanism for attitude change.

\section{References}

Angelini, J. R., Nadorff, P. G., Shin, M., Gantz, W., \& Lang, A. (2006). Stigma! How American television portrays people with mental illness and those who care for them. Presented at the annual conference of the International Communication Association, Dresden, Germany.

Bracken, C. C. (2005). Are we together? Exploring the similarities between the concepts of transportation imagery model and presence and their possible impact on persuasion. Proceedings from the 5th International Association for Presence Research Meeting, (pp. 125-129). Cleveland, OH.

Bracken, C. C., Pettey, G., Guha, T., \& Rubenking, B. (2010). Sounding out small screens and telepresence: The impact of audio, screen size, and pace. Journal of Media Psychology, 22, 125-137. http://dx.doi.org/10.1027/1864-1105/a000017

Busselle, R. W., \& Bilandzic, H. (2006). Experiential engagement in filmic narratives. Paper presented at the annual meeting of the International Communication Association. Dresden, Germany.

Busselle, R., \& Bilandzic, H. (2009). Measuring narrative engagement. Media Psychology, 12, 321-347. http://dx.doi.org/10.1080/15213260903287259

Caputo, N. M., \& Rouner, D. (2011). Narrative processing of entertainment media and mental illness stigma. Health Communication, 26, 595-604. http://dx.doi.org/10.1080/10410236.2011.560787

Chung, K. F., Chen, E. Y., \& Liu, C. S. (2001). University students' attitudes towards mental patients and psychiatric $\begin{array}{lllll}\text { treatment. International Journal of } & \text { Social } & \text { Psychiatry, 47(2), } & \text { 63-72. }\end{array}$ http://dx.doi.org/10.1177/002076400104700206

Corrigan, P. W., Green, A., Lundin, R., Kubiak, M. A., \& Penn, D. L. (2001). Familiarity with and social distance from people who have serious mental illness. Psychiatric Services, 52, 953-958. http://dx.doi.org/10.1176-appi.ps.52.7.953

Couture, S., \& Penn, D. (2003). Interpersonal contact and the stigma of mental illness: A review of the literature. Journal of mental health, 12(3), 291-305. http://dx.doi.org/10.1080/09638231000118276

Coverdale, J., Nairn, R., \& Claasen, D. (2002). Depictions of mental illness in print media: A prospective national sample. Australian and New Zealand Journal of Psychiatry, 36, 697-700. http://dx.doi.org/10.1046/j.1440-1614.2002.00998.x

Crisp, A. H., Gelder, M. G., Rix, S., Meltzer, H. I., \& Rowlands, O. J. (2000). Stigmatization of people with mental illness. British Journal of Psychiatry, 177, 4-7. http://dx.doi.org/10.1192/bjp.177.1.4

Dal Cin, S., Zanna, M. P., \& Fong, G. T. (2004). Narrative persuasion and overcoming resistance. In E. S. Knowles \& J. A. Linn (Eds.), Resistance and Persuasion (pp. 175-191). Mahwah, NJ: Lawrence Erlbaum.

Diefenbach, D. L., \& West, M. D. (2007). Television and attitudes toward mental health issues: Cultivation analysis and the third - person effect. Journal of Community Psychology, 35, 181-195. http://dx.doi.org/10.1002/jcop.20142

Gerbner, G. (1998). Images of mental illness in the mass media. Media Development, 45(2), 38-39.

Gerbner, G., Gross, L. Morgan, M., \& Signorielli, N. (1980). The "mainstreaming" of America: Violence profile 11. Journal of Communication, 30, 10-29. http://dx.doi.org/0.1111/j.1460-2466.1980.tb01987.x

Gerrig, R. J. (1993). Experiencing narrative worlds. New Haven, CT: Yale University Press.

Green, M. C., \& Brock, T. C. (2000). The role of transportation in the persuasiveness of public narratives. Journal of Personality and Social Psychology, 79, 701-721. http://dx.doi.org/10.1037/0022-3514.79.5.701

Green, M. C., \& Brock, T. C. (2002). In the Mind's eye: Transportation-imagery model of narrative persuasion. In M.C. Green, J. J. Strange, \& T. C. Brock (Eds.). Narrative impact: Social and Cognitive Foundations. (pp.315-341). Mahwah, NJ: Lawrence Erlbaum.

Igartua, J. J., \& Barrios, I. (2012). Changing real - world beliefs with controversial movies: Processes and mechanisms of narrative persuasion. Journal of Communication, 62(3), 514-531. http://dx.doi.org/10.1111/j.1460-2466.2012.01640.x

IJsselsteijn, W. A. (2003). Presence in the past: What can we learn from media history? In: Riva, G., Davide, F., \& IJsselsteijn, W. A., (eds.), Being There - Concepts, Effects and Measurements of User Presence in Synthetic Environments, Amsterdam: IOS Press. pp. 17-40. 
Ingamells, S., Goodwin, A. M., \& John, C. (1996). The influence of psychiatric hospital and community residence labels on social rejection of the mentally ill. British Journal of Clinical Psychology, 35, 359-367. http://dx.doi.org/10.1111/j.2044-8260.1996.tb01190.x

Kim, T., \& Biocca, F. (1997). Telepresence via television: Two dimensions of telepresence may have different connections to memory and persuasion. Journal of Computer-Mediated Communication, 3, 0-0. http://dx.doi.org/10.1111/j.1083-6101.1997.tb00073.x

Klin, A., \& Lemish, D. (2008). Mental disorders stigma in the media: Review of studies on production, content, and influences. Journal of Health Communication, 13(5), 434-449. http://dx.doi.org/10.1080/10810730802198813

Lee, E., \& Leets, L. (2002). Persuasive storytelling by hate groups online. American Behavioral Scientist, 45, 927-957. http://dx.doi.org/10.1177/0002764202045006003

Li, H., Daugherty, T., \& Biocca, F. (2002). Impact of 3-D advertising on product knowledge, brand attitude, and purchase intention: The mediating role of presence. Journal of Advertising, 31, 43-57. http://dx.doi.org/10.1080/00913367.2002.10673675

Link, B. G., Phelan, J. C., Bresnahan, M., Stueve, A., \& Pescosolido, B. A. (1999). Public conceptions of mental illness: labels, causes, dangerousness, and social distance. American Journal of Public Health,89, 1328-1333. http://dx.doi.org/10.2105/AJPH.89.9.1328

Lombard, M., \& Ditton, T. (1997). At the heart of it all: The concept of presence. Journal of Computer -Mediated Communication, 3(2), 0-0. http://dx.doi.org/10.1111/j.1083-6101.1997.tb00072

Lombard, M., Weinstein, L., \& Ditton, T. (2011, October). Measuring telepresence: The validity of the Temple Presence Inventory (TPI) in a gaming context. Presented at the 2011 annual conference of the International Society for Presence Research (ISPR), Edinburgh, Scotland.

Moyer, G. E., \& Nabi, R. L. (2010). Explaining the effects of narrative in an entertainment television program:

Murphy, S. T., Frank, L. B., Moran, M. B., \& Patnoe - Woodley, P. (2011). Involved, transported, or emotional? Exploring the determinants of change in knowledge, attitudes, and behavior in Entertainment - Education. Journal of Communication, 61, 407-431. http://dx.doi.org/10.1111/j.1460-2466.2011.01554.x

Overcoming resistance to persuasion. Human Communication Research,36(1), 26-52. http://dx.doi.org/10.1111/j.1468-2958.2009.01367.x

Penn, D. L., Kommana, S., Mansfield, M., \& Link, B. G. (1999). Dispelling the stigma of schizophrenia: II. The impact of information on dangerousness. Schizophrenia Bulletin, 25(3), 437-446.

Pescosolido, B. A. (2013). The public stigma of mental illness: What do we think; What do we know; What can we prove? Journal of Health and Social Behavior, 54, 1-21. http://dx.doi.org/10.1177/0022146512471197

Philo, G. (Ed.). (1996). Media and Mental Distress. London: Longman.

Pirkis, J., Blood, R. W., Francis, C., \& McCallum, K. (2006). On-screen portrayals of mental illness: Extent, nature, and impacts. Journal of Health Communication, 11, 523-541. http://dx.doi.org/10.1080/10810730600755889

Read, J., \& Harre, N. (2001). The role of biological and genetic causal beliefs in the stigmatization of 'mental patients.' Journal of Mental Health, 10, 223-235. http://dx.doi.org/10.1080/09638230123129

Ritterfield, U., \& Jin, S. A. (2006). Addressing media stigma for people experiencing mental illness using an entertainment-education strategy. Journal of Health Psychology, 11, 247-267. http://dx.doi.org/10.1177/1359105306061185

Robert Wood Johnson Foundation. (1992, November). The Robert Wood Johnson Foundation Program on mental illness: An overview, 41, (pp. 1212-1216). American Psychiatric Association.

Rogers, E. M. (2003). Diffusion of innovations (5th ed.). New York: Free Press.

Rose, D. (1998). Television, madness and community care Journal of Community \& Applied Social Psychology, 8 , 213-228. http://dx.doi.org/10.1002/(SICI)1099-1298(199805/06)8:3<213::AID-CASP449>3.0.CO;2-C

Schneider, E. F. (2004). Death with a story: How story impacts emotional, motivational, and physiological responses to first-person shooter video games. Human Communication Research, 30, 361-365. http://dx.doi.org/10.1111/j.1468-2958.2004.tb00736.x

Schomerus, G., Schwahn, C., Holzinger, A., Corrigan, P. W., Grabe, H. J., Carta, M. G., \& Angermeyer, M. C. (2012). Evolution of public attitudes about mental illness: a systematic review and meta - analysis. Acta Psychiatrica 
Scandinavica, 125, 440-452. http://dx.doi.org/10.1111/j.1600-0447.2012.01826.x

Sieff, E. (2003). Media frames of mental illnesses: The potential impact of negative frames. Journal of Mental Health, 12, 259-269. http://dx.doi.org/10.1080/0963823031000118249.

Signorielli, N. (1989). The stigma of mental illness on television. Journal of Broadcasting \& Electronic Media, 33, 325-311. http://dx.doi.org/10.1080/08838158909364085

Skalski, P., \& Tamborini, R. (2007). The role of social presence in interactive agent-based persuasion. Media Psychology, 10, 385-414. http://dx.doi.org/10.1080/15213260701533102

Slater, M. D. (2002). Entertainment education and the persuasive impact of narratives. In M.C. Green, J. J. Strange, \& T. C. Brock (Eds.), Narrative impact: Social and cognitive foundations (pp. 157-182). Thousand Oaks, CA: Sage

Slater, M. D., \& Rouner, D. (2002). Entertainment—education and elaboration likelihood: Understanding the processing of narrative persuasion. Communication Theory, 12, 173-191. http://dx.doi.org/10.1111/j.1468-2885.2002.tb00265.x

Slater, M. D., Rouner, D., \& Long, M. (2006). Television dramas and support for controversial public policies: Effects and mechanisms. Journal of Communication, 56, 235-252. http://dx.doi.org/10.1111/j.1460-2466.2006.00017.x

Stitt, C. R., \& Nabi, R. L. (2005). The persuasive impact of narratives: A comparison across message types and modalities. Paper presented at the annual meeting of the International Communication Association. New York, New York.

Tal-Or, N., Boninger, D. S, Poran, A., Gleicher, F. (2004). Counterfactual thinking as a mechanism in narrative persuasion. Human Communication Research, 30, 301-328. http://dx.doi.org/10.1111/j.1468-2958.2004.tb00734.x

Taylor., S. M., \& Dear, M. J. (1981). Scaling community attitudes toward the mentally ill. Schizophrenia Bulletin, 7 , 225-240. http://dx.doi.org/10.1093/schbul/7.2.225

Thornton, J. A., \& Wahl, O. F. (1996). Impact of a newspaper article on attitudes toward mental illness Journal of Community Psychology, 24, 17-25.

http://dx.doi.org/10.1002/(SICI)1520-6629(199601)24:1<17::AID-JCOP2>3.0.CO;20

Tukachinsky, R. (2014). Experimental manipulation of psychological involvement with media. Communication Methods and Measures, 8, 1-33. http://dx.doi.org/10.1080/19312458.2013.873777

Wahl, O. F. (1995). Media madness: Public images of mental illness. New Brunswick, NJ: Rutgers University Press.

Wahl, O. F., \& Lefkowitz, J. Y. (1989). Impact of a television film on attitudes toward mental illness. American

Wahl, O. F., \& Roth, R. (1982). Television images of mental illness: Results of a metropolitan Washington media watch, Journal of Broadcasting, 26, 599-605. http://dx.doi.org/10.1080/08838158209364028

Wirth, W., Hartmann, T., Bocking, S., Vorderer, P., Klimmt, C., Schramm, H., Saari, T., Laarni, J., Ravaja, N., Gouveia, F., R., Biocca, F., Sacau, A., Jancke, L., Baumgartner, P. J., \& Jancke, P. (2007). A process model of the formation of spatial presence experiences. Media Psychology, 9, 493-52. http://dx.doi.org/10.1080/15213260701283079

\section{(cc) $\mathrm{BY}$}

This work is licensed under a Creative Commons Attribution 3.0 License. 